\title{
BMJ Open 'Beats the alternative but it messes up your life': Aboriginal people's experience of haemodialysis in rural Australia
}

\author{
Elizabeth F Rix, ${ }^{1}$ Lesley Barclay, ${ }^{1}$ Janelle Stirling, ${ }^{1}$ Allison Tong, ${ }^{2}$ Shawn Wilson ${ }^{1}$
}

To cite: Rix EF, Barclay L, Stirling J, et al. 'Beats the alternative but it messes up your life': Aboriginal people's experience of haemodialysis in rural Australia. BMJ Open 2014;4:e005945. doi:10.1136/ bmjopen-2014-005945

- Prepublication history for this paper is available online. To view these files please visit the journal online (http://dx.doi.org/10.1136/ bmjopen-2014-005945).

Received 24 June 2014 Revised 8 August 2014 Accepted 8 August 2014

CrossMark

\section{${ }^{1}$ University Centre for Rural Health, The University of Sydney, Lismore, New South Wales, Australia \\ ${ }^{2}$ Sydney School of Public Health, The University of Sydney, Sydney, New South Wales, Australia}

\section{Correspondence to} Elizabeth F Rix; Elizabeth. rix@ncahs.health.nsw.gov.au

\section{ABSTRACT}

Objectives: Australian Aboriginal people have at least eight times the incidence of end-stage kidney disease, requiring dialysis, as the non-Aboriginal population. Provision of health services to rural Aboriginal people with renal disease is challenging due to barriers to access and cultural differences. We aimed to describe the experiences of Aboriginal people receiving haemodialysis in rural Australia, to inform strategies for improving renal services.

Design: A qualitative design incorporating: Indigenist research methodology and Community Based Participatory Research principles. In-depth interviews used a 'yarning' and storytelling approach. Thematic analysis was undertaken and verified by an Aboriginal Community Reference Group.

Setting: A health district in rural New South Wales, Australia.

Participants: Snowball sampling recruited 18 Aboriginal haemodialysis recipients.

Results: Six themes emerged which described the patient journey: 'The biggest shock of me life,' expressed the shock of diagnosis and starting the dialysis; 'Beats the alternative but it messes up your life,' explained how positive attitudes to treatment develop; 'Family is everything', described the motivation and support to continue dialysis; 'If I had one of them nurses at home to help me', depicted acute hospital settings as culturally unsafe; 'Don't use them big jawbreakers', urged service providers to use simple language and cultural awareness; 'Stop 'em following us onto the machine', emphasised the desire for education for the younger generations about preventing kidney disease. An Aboriginal interpretation of this experience, linked to the analysis, was depicted in the form of an Aboriginal painting.

Conclusions: Family enables Aboriginal people to endure haemodialysis. Patients believe that priorities for improving services include family-centred and culturally accommodating healthcare systems; and improving access to early screening of kidney disease. Inclusion of Aboriginal patients in cultural education for renal staff is recommended. Providing opportunities for patients to educate young Aboriginal people about kidney disease prevention may be highly effective and empowering.

\section{Strengths and limitations of this study}

- This is the first qualitative study to focus on the perspectives of rural Australian Aboriginal people on haemodialysis.

- Our study included $86 \%$ of the Aboriginal patients receiving haemodialysis in the rural region where the study took place.

- Aboriginal people from one rural region of Australia were included; therefore, transferability is uncertain.

\section{INTRODUCTION}

In Australia, Aboriginal people have multiple risk factors for renal disease. ${ }^{1}$ Significant disparities exist between the numbers of Aboriginal people with renal failure compared with non-Aboriginal Australians. ${ }^{2}$ Aboriginal and Torres Strait Islander people are eight times more likely to have chronic kidney disease (CKD) progressing to endstage kidney disease (ESKD) than the general population. ${ }^{34}$

Patients on haemodialysis (HD) suffer loss of independence and freedom, inability to work, social isolation and fear of the future. $^{5}{ }^{6}$ These are reported in other Indigenous people with ESKD. ${ }^{7}{ }^{8}$ Studies in Canada have found that for Indigenous patients receiving HD, access, relocation, separation from family and cultural issues influence health outcomes. ${ }^{9}$ Similarly, in the Australian context, relocation and separation have profound negative impacts on individuals, families and whole communities. ${ }^{10-12}$

Haemodialysis can be performed in-centre or at home. The majority of Australian Aboriginal people receive HD in tertiary renal units in large hospitals or smaller satellite units. ${ }^{13}$ Patients often form long-term relationships with staff in renal units. These relationships can be vehicles for transferring information and are therapeutic in nature. ${ }^{14}$ When these relationships do not work well, the resulting disempowerment and 
dislocation in patients' lives can have a devastating effect on their already compromised health and family. ${ }^{9} 15$

A better understanding of the lived experience of Aboriginal HD patients can inform service provision to improve clinical outcomes and quality of life. The perspectives of Australian Aboriginal people receiving HD in rural areas, where the majority of Aboriginal people reside, remain understudied. ${ }^{15-17}$ This is the first qualitative study to explore rural dwelling Aboriginal people's experience and perspectives on being HD recipients.

The aim of this paper is to describe the experience and perspectives of rural Aboriginal people on haemodialysis. The findings may be used to inform strategies for service improvement and improve the health and wellbeing of rural dwelling Aboriginal people with CKD.

\section{METHODS}

\section{Context}

This study examined the experience and perceptions of Aboriginal people receiving $\mathrm{HD}$ in an Australian regional area to which rural patients travel for treatment. This region has $3.5 \%{ }^{18}$ of the population identifying as Aboriginal or Torres Strait Islanders; however, at the time of this study, they represented $18 \%$ of those on HD. The rising incidence of type 2 diabetes is resulting in an increasing number of Aboriginal people experiencing renal failure at a much younger age than non-Aboriginal Australians. ${ }^{19}$

The study was embedded in an Indigenist research paradigm, using Indigenous methodologies ${ }^{20} 21$ and principles of Community Based Participatory Research (CBPR) ${ }^{22}$ Indigenous scholars describe Aboriginal ways of knowing and being as located within relationships. The fusion of Indigenist and CBPR methodologies created a collaborative and participatory approach to a study that is evident in the analysis reported in this paper. Relationships are central to working in partnership with the community under investigation. Prior to the start of the study, a Community Reference Group

\begin{tabular}{|c|c|c|}
\hline Participant characteristic & $\mathbf{N}$ & Per cent \\
\hline \multicolumn{3}{|l|}{ Gender } \\
\hline Male & 9 & (50) \\
\hline Female & 9 & (50) \\
\hline \multicolumn{3}{|l|}{ Age (years) } \\
\hline $30-39$ & 4 & (22) \\
\hline $40-49$ & 2 & (11) \\
\hline $50-59$ & 8 & (44) \\
\hline $60-69$ & 3 & (17) \\
\hline $70-79$ & 1 & (6) \\
\hline \multicolumn{3}{|c|}{ Time on haemodialysis (years) } \\
\hline$<1$ & 2 & (12) \\
\hline $1-5$ & 3 & (17) \\
\hline $5-10$ & 10 & (56) \\
\hline$>10$ & 3 & (16) \\
\hline
\end{tabular}

(CRG) of 10 members was formed. This group included Aboriginal renal patients, elders and Aboriginal health workers and provided the researchers with cultural and analytic guidance, ensuring that Aboriginal perspectives were accurately represented.

An integral part of the Indigenous methodology is to protect the raw narrative in the presentation of the results. ${ }^{23}$ Therefore, the themes and subthemes were presented in the words of participants. According to the Australian Indigenous scholar Rigney (who created the term Indigenist research), 'Privileging Indigenous voices in Indigenous research' is key to 'addressing their history of exploitation, suspicion, misunderstanding and prejudice' (ref. 24, p.116). This approach also fulfils the wishes of members of the CRG guiding the research. In accordance with Indigenist methods, where relational accountability is central, the research team must be acknowledged and their positioning understood. ${ }^{25} 26$ The first author (EFR) is a renal nurse, researcher and the wife of a man with CKD. The complexity of her overlapping roles posed ethical, cultural and methodological challenges requiring a deeply reflexive approach, which became central to the methods used. ${ }^{27}$ The coauthors comprise an experienced researcher with Aboriginal people, two Indigenous scholars and a social scientist.

\section{Participants}

Aboriginal patients were eligible to participate if they were aged over 18 and received HD through the renal service in the study. Fliers were placed at dialysis units and Aboriginal controlled health services (ACCHS). Potential participants contacted the first author if interested. A form of snowballing via word of mouth ${ }^{28}$ within the Aboriginal dialysis community extended the study, with early interviewees independently endorsing participation to fellow patients. Of the 21 eligible Aboriginal HD patients in this region, 18 participated. The three who did not participate comprised one who declined and two who were too acutely unwell to participate (table 1).

\section{Data collection}

Interviews were conducted by EFR at a location preferred by participants (in most cases their homes) between March and November 2011. A 'yarning' technique was used throughout the interviews. Yarning is a word used by some Aboriginal people and means 'let's have a chat'. ${ }^{29}$ In a research context, yarning through interviews involves an informal and reciprocal exchange of information congruent with Aboriginal communication styles. This approach is culturally appropriate, enhances participant rapport and promotes open and honest discussion. ${ }^{30}$ Initial rapport was established through 'yarning' about topics unrelated to the study. While there was no set interview guide, participants were encouraged, with consistent prompts, to 'yarn' about their experiences with renal service providers and to 
suggest ways for improving their dialysis experience. All interviews were recorded and transcribed verbatim.

Field notes describing the participant characteristics, level of disclosure, family dynamics and general context of each person's story were recorded after each interview. $^{28}$

\section{Ethical considerations}

Ethical approval was obtained from: the North Coast Area Health Service of New South Wales, the Aboriginal Health and Medical Research Council of New South Wales, and The University of Sydney's Human Research Ethics Committees. All participants signed an informed consent form.

\section{Data analysis}

Transcripts were entered into NVivo 9 (QSR International). The analysis used Strauss' grounded theory coding methods, where coding moves from open (describing concepts) to axial (developing concepts) to selective coding, focusing on one category at a time to build, discuss and reflect on explanations from dense coding. ${ }^{31}$ Preliminary themes were developed by EFR by relistening to interviews, re-reading transcripts and notetaking. EFR inductively coded concepts in the transcripts, grouping similar concepts. The CRG and the coauthors then contributed to the interpretive analysis of the descriptive themes. EFR then searched for relationships between these interpretations and further substantiation within the data. Final themes and interpretations were validated by the CRG.

\section{Rigour}

To confirm the analysis, several transcripts were reviewed independently by the coauthors, then discussed and agreed across the researchers. Preliminary findings were presented to the CRG for critique and comment. Members confirmed that the analysis reflected their own experiences of receiving dialysis, or if health workers, their work with Aboriginal HD recipients. Discussions and feedback from this group helped clarify themes and verified the analysis. The Aboriginal artwork depicting study results in cultural imagery was painted by an Aboriginal woman on HD after this session, demonstrating that the analysis 'rang true' to her as a patient (figure 1).

\section{RESULTS}

\section{Parallel Indigenous and western biomedical perspectives}

The results are presented from an Aboriginal perspective and linked to the word-based data (ie, themes presented as quotes). This parallel Aboriginal interpretation illustrates the journey 'along the river of life' as experienced by Aboriginal people on HD. Themes are presented in the words of participants to maintain authenticity and the spirit of Aboriginal leadership throughout the study. They have been transposed into 'western' health service-related concepts (figure 2).

Six themes emerged reflecting the trajectory of the patient's journey, ${ }^{32}$ from diagnosis to the acceptance of their ESKD and motivation to continue treatment. The Aboriginal artwork depicts this journey under the 'Sun', which represents the centrality of 'Family', with the sunrays depicting the love and support of family that enables Aboriginal HD patients to continue their journey along the 'river of life' once they start dialysis. The six footsteps depict each stage of their journey along 'the river of life'.

\section{'The biggest shock of me life'}

Most participants reported being diagnosed late in the progression of their CKD, feeling they had little education prior to the start of HD. In expressing their reaction to the diagnosis and start of HD, they felt that life as they had known it was suddenly over or changed forever. "It was the biggest shock of me life...one day I was running around like a mad thing and all of a sudden my life was taken away from me" [Woman, 50s]. Despite having family members with CKD, some felt invincible and thought CKD could not happen to them.

Yeah you think I'd have woke up a bit what with my father being on it, and passing away on it, but I just thought it'll never happen to me, as a lot of young fellas do. I was only 34 when I started. [Man, 30s]

'I didn't know I had kidney disease'

Many participants described being unaware of their ESKD until they suddenly became ill, requiring hospitalisation.

I didn't know I had kidney problems cause I was pretty active, fishin' huntin' golfin'...until one day I felt a bit crook there...so they rushed me to hospital and when I woke up I was in the intensive care ward... and they said 'Oh you have to go down to dialysis and get blood into you, your kidneys have had it'. [Man, 50s]

Many initially felt overwhelmed by the enormity of the situation and the amount of information they were required to absorb.

But that time of first meetings with the specialists, with renal nurses, they was explaining a lot of things...which actually just went in one ear and out the other, because you're just still going through the initial shock. [Woman, $50 \mathrm{~s}]$

'I didn't know what to expect, nobody told me'

Participants believed they had not received adequate predialysis education. They felt unprepared and anxious. One participant described feeling fearful and helpless during her first dialysis session.

Now I had no training, nobody talked to me about what to expect, when I first went on...I could not believe what 


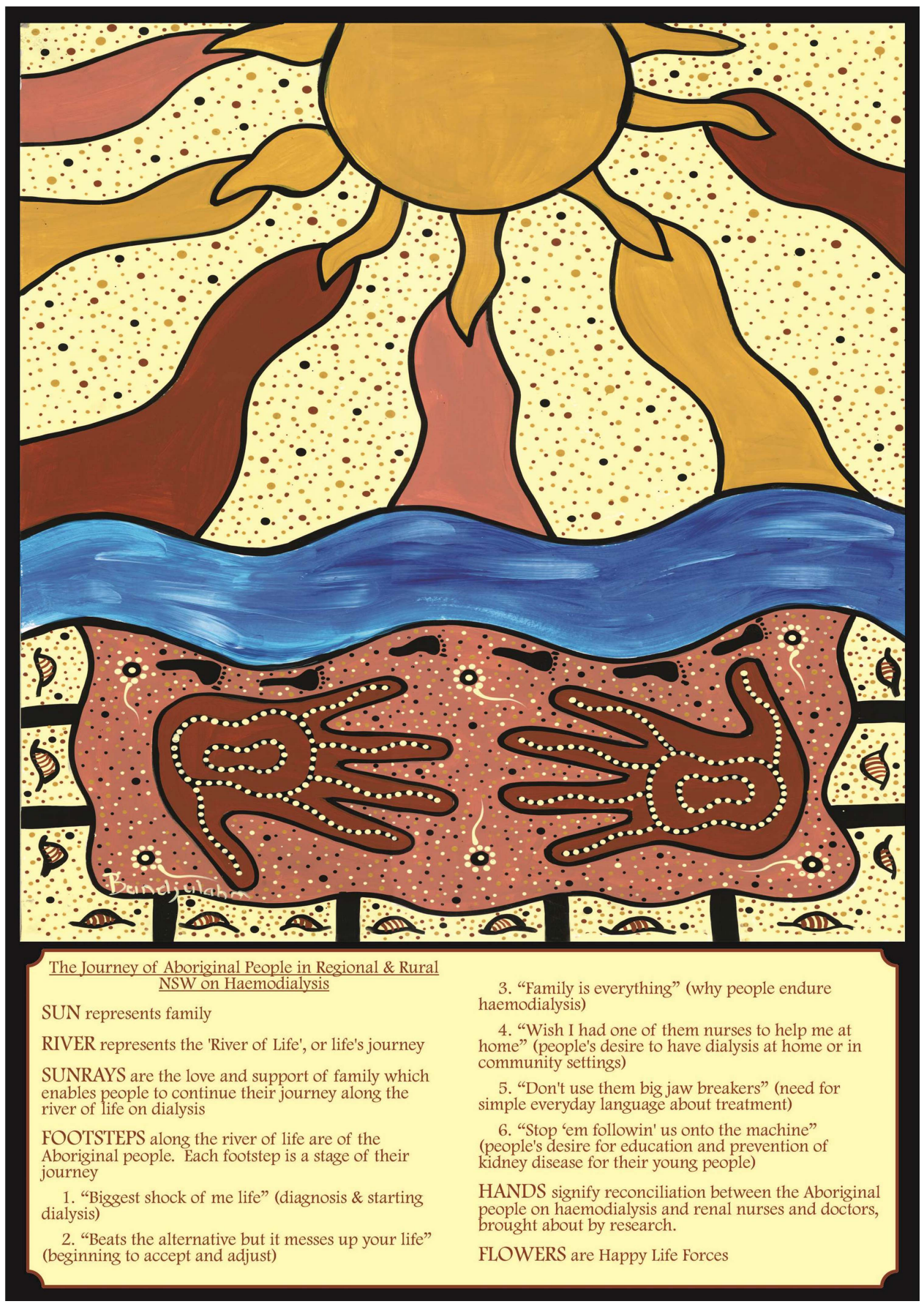

Figure 1 The journey of Aboriginal people on haemodialysis in rural Australia.

was going on with me...I had the most horrible anxiety attack. I just wanted to scream, pull the needles out and run...They just come along and jabbed me with the needles, strapped me up with sticky tape and started pressin' buttons. [Woman, 50s]

Another woman expressed her distress when doctors talked among themselves at her bedside without telling her she was about to start dialysis.

If the doctor had explained to me that I was going onto the kidney machine I would have by all means understood. He talked with the other doctors and I could hear him saying something about kidney failure, but they never once told me that I was getting on the kidney machine. [Woman, 40s]

'Beats the alternative but it messes up your life' Participants believed they developed a more positive attitude once they became used to HD. They appreciated it was life-sustaining and accepted that regular treatment was now part of their life. "I start to get used to the idea now, at least it keeps me alive". [Man, 50s] 
FAMILY - Motivation \& support to continue haemodialysis

\begin{tabular}{|c|c|c|c|c|c|}
\hline$\downarrow$ & $\downarrow$ & $\downarrow$ & $\downarrow$ & $\downarrow$ & $\downarrow$ \\
\hline $\begin{array}{l}\text { 'The biggest } \\
\text { shock of me life' } \\
\text { Distress and shock } \\
\text { of diagnosis and } \\
\text { starting dialysis }\end{array}$ & $\begin{array}{l}\text { 'Beats the } \\
\text { alternative but it } \\
\text { messes up your } \\
\text { life' } \\
\text { Developing positive } \\
\text { attitudes towards } \\
\text { treatment }\end{array}$ & $\begin{array}{c}\text { 'Family is } \\
\text { everything' } \\
\text { Motivation and } \\
\text { support to continue } \\
\text { treatment }\end{array}$ & $\begin{array}{c}\text { 'If I had one of } \\
\text { them nurses to } \\
\text { help me at home' } \\
\text { Preference for } \\
\text { home or community- } \\
\text { based dialysis }\end{array}$ & $\begin{array}{c}\text { ‘Don't use them } \\
\text { big jaw breakers' } \\
\text { Overwhelmed by } \\
\text { medical terminology } \\
\text { \& lack of cultural } \\
\text { safety }\end{array}$ & $\begin{array}{l}\text { 'Stop em } \\
\text { followin' us onto } \\
\text { the machine' } \\
\text { Prevent CKD } \\
\text { in the next } \\
\text { generation }\end{array}$ \\
\hline $\begin{array}{l}\qquad \\
\qquad \\
\text { 'Didn't know I had } \\
\text { kidney disease' } \\
\text { Early diagnosis to } \\
\text { prevent crisis and } \\
\text { shock initiation }\end{array}$ & $\begin{array}{l}\quad \downarrow \\
\text { 'You dig yourself a } \\
\text { very lonely hole' } \\
\text { loneliness and } \\
\text { isolation, even } \\
\text { within their family }\end{array}$ & $\begin{array}{l}\qquad \downarrow \\
\text { 'They like } \\
\text { fussing } \\
\text { over me' } \\
\text { Love and support of } \\
\text { family gives security } \\
\text { and support }\end{array}$ & $\begin{array}{l}\qquad \downarrow \\
\text { 'I thought I had } \\
\text { come to the } \\
\text { morgue' } \\
\text { Anguish and } \\
\text { discomfort in large } \\
\text { acute renal units }\end{array}$ & $\begin{array}{l}\qquad \\
\text { 'Staff need to } \\
\text { have Aboriginal } \\
\text { cultural values } \\
\text { about 'em } \\
\text { Lack of cultural } \\
\text { awareness }\end{array}$ & $\begin{array}{l}\downarrow \\
\text { 'We gotta get em in } \\
\text { the schools' } \\
\text { School-based } \\
\text { health promotion } \\
\text { 'They don't care }\end{array}$ \\
\hline $\begin{array}{l}\text { 'Nobody told me } \\
\text { what to expect' } \\
\text { Participants } \\
\text { reported lack of pre- } \\
\text { dialysis education }\end{array}$ & $\begin{array}{l}\text { 'Your life is } \\
\text { committed to that } \\
\text { machine' } \\
\text { Severe limitations } \\
\text { on ability to fulfil } \\
\text { family obligations } \\
\text { 'But finally I come } \\
\text { to terms with it' } \\
\text { Acceptance of } \\
\text { dialysis as part of } \\
\text { daily life }\end{array}$ & $\begin{array}{l}\text { 'Hard on the } \\
\text { Jarjums' } \\
\text { Burden of care on } \\
\text { children caring for } \\
\text { parents } \\
\text { 'Too many funerals } \\
\text { for us mob' } \\
\text { 'Spiral of grief': } \\
\text { Early mortality from } \\
\text { chronic disease }\end{array}$ & $\begin{array}{l}\text { 'It's my second } \\
\text { home now' } \\
\text { Smaller satellite } \\
\text { units more } \\
\text { comfortable places } \\
\text { to be }\end{array}$ & $\begin{array}{l}\text { impacts } \\
\text { negatively on } \\
\text { communication } \\
\text { Fear of } \\
\text { interaction with } \\
\text { health services } \\
\text { from traumatic } \\
\text { experience of } \\
\text { extended family } \\
\text { in the past }\end{array}$ & $\begin{array}{l}\text { what they eat' } \\
\text { Awareness of poor } \\
\text { diet and impact on } \\
\text { kidney health }\end{array}$ \\
\hline
\end{tabular}

Figure 2 Thematic schema—health service implications for Aboriginal people on haemodialysis in rural New South Wales, Australia.

\section{'You dig yourself a very lonely hole'}

Some participants expressed feeling lonely and isolated. Several felt they wanted to die, as they believed their family members could not understand the enormity of the physical and emotional impacts of HD. They reported overcoming these thoughts, however, once they came to terms with HD. "You are stuck with it, all alone and that is when I started feeling real bad...I was going to do myself in...but I've sort of got used to it now." [Man, 40s]

\section{'Your life is committed to that machine'}

Participants became aware of the drastic changes in their lifestyle and restrictions imposed by dialysis. Being unable to work at home or travel to paid employment, visit family or take a holiday was common.

Dialysis changes our life, just like that you know. Yeah we can't even do things and can't go anywhere...used to go out every day, go away to get work. Now can't even push the mower, it messes the fistula up. [Man, 30s]

\section{'But finally I come to terms with it'}

Participants recognised that HD was:

A big adjustment in your life and your lifestyle, you can either do it and get on with it or, it's your choice. Life is what you make of it. This is what I have to do for the rest of my life to look after myself. [Woman, 60s]

\section{'Family is everything'}

Participants described their motivation to stay alive on HD for their families, wanting to see their children and grandchildren grow up. "I just live day by day, and I just thinkin' of my kids all the time, yeah that's what keepin' me goin' seeing my boys, seeing the littlies and my daughter" [Woman, 30s]. People described high levels of support and care from their families, with offers to donate kidneys or support them to have home HD.

My oldest boy put his hand up and said "well Mum I'll give you my kidney", my other son said 'Mum I'll come and be your carer'. 'And my baby son said "I'll learn the machine with you". So straight away the family was onto it, wanted to deal with it with me' [Woman, 50s].

\section{'They like fussing over me'}

Participants felt secure and motivated to persevere with HD because of the love and care of family. "Anything I need they're there, you know it's not just like going in with the flu, you need a lot of support, there's a lifelong commitment. And you've got to have that support there" [Woman, 60s].

\section{'Hard on the jarjums (kids)'}

With the majority of patients being in their $40 \mathrm{~s}$ and $50 \mathrm{~s}$, there was a common theme of not wanting to have their teenaged and young adult children burdened with their care. 'I don't want her stuck here lookin' after me all 
the time, cause she only young and she wants to go and have a break" [Woman, 40s].

\section{'There's too many funerals for us mob'}

All participants had family members with chronic disease, with many passing away prematurely. A universal theme of 'too many funerals' is testament to the high levels of sickness, grief and loss. "I started dialysis in my late 20's and lost me mother and father at an early age and...our older sister passed too" [Man, 30s], and

There's only me and another fella now, in our age bracket only alive. The rest died...It's sad, cause they would have been the same age as me and I could relate to those fellas you know, sit down and have a good yarn to them. [Man, 50s]

\section{'If I had one of them nurses at home to help me'}

Most participants felt dissatisfied with current services, expressing their preference for home HD supported by renal nurses. Many were reluctant to ask their family to take responsibility for home dialysis in addition to caring duties. Most, however, would be willing to have HD at home with increased access to clinical support. "She's not really keen to do it. I'm wanting to do it, but she's a bit frightened that something might go wrong and she don't wanna do it and take responsibility" [Man, 30s].

\section{'I thought I had come to the morgue'}

Participants accessing HD in the tertiary unit experienced the most distress and they struggled to accept having to spend 3 days/week in an environment which they felt lacked cultural understanding. They expressed significant anxiety and discomfort at what they considered an alien environment. Being an outpatient beside acutely ill inpatients was confronting. People perceived the staff as too busy to talk and develop relationships with them. "To be quite honest I was a bit uncomfortable in going there... I felt like I was just a statistic, they didn't get to know you like the ones up here" (in a smaller unit) [Man, 30s].

When I looked round I seen all these old white people sittin' in the chairs and like I was walkin' into a morgue, very quiet...It were just like it was dead in there and I had to go in there and be treated for the dialysis. [Man, 60s]

\section{'It's my second home now'}

In contrast, participants dialysing at smaller satellite units found them more welcoming. Staff had time to converse and develop supportive relationships. Participants appreciated the opportunity to build relationships with other patients and felt that the atmosphere was more conducive to friendly conversation than in the large acute unit. "We have really good staff, I think because it's a small unit. It's like everybody becomes closer, they become part of your family, Aboriginal and non-Aboriginal" [Woman, 60s].

\section{'Don’t use them big jawbreakers'}

Many participants were unable to understand information given to them, feeling overwhelmed by medical terms used when clinicians were explaining their ESKD and treatment. "When the doctors and staff explain things to the Aboriginal patient, I found what they do, they talk in university words, big jaw breakers, instead of just talking plain English so they can understand it" [Man, 50s]. Participants expressed a reluctance to ask questions when they did not understand information. "But the majority of our people are very shy, they frightened to ask questions of anybody, specially a white person and that's why they find they got a few problems, because they frightened to ask for some advice" [Man, 50s].

People described their fears as they remembered the racism of the past when children could be taken from parents if they sought medical treatment. "If our mothers took us to the doctors for any reason then the welfare would come and take us kids away" [Woman, 50s].

\section{'Staff need to have some Aboriginal cultural values about 'em'}

Participants frequently commented on what they perceived to be a lack of cultural awareness among renal staff. They felt forced to yield themselves to the care of staff who they believed had little understanding of Aboriginal cultural issues. Many felt staff did not understand Aboriginal people's reasons for prioritising family commitments over their treatment. Others felt disrespected, ignored or discriminated against because of their race. "I think they need to get back to school... learn about Aboriginal issues and cultural values. Because half the time their attitude towards Aboriginal issues and values keeps Aboriginals away" 'Man, 50s].

A divergence from this experience occurred for participants dialysing at a unit with access to an Aboriginal support person. They felt understood and supported and able to call on her when they needed help or were struggling with their treatment.

I just wanted to live a normal life and I knew that I couldn't, I thought I could and I used to miss days...the hospital would send $* * * * * *$ to come looking for me cause she knew which places I'd be and knows my family. She understood why I didn't want to be there. [Male, 30s]

A participant who had worked in Aboriginal health stated that cultural awareness training needed to be delivered by Aboriginal people with knowledge and experience of being on dialysis.

There be no good just any old black fella coming and talking to our staff about this because that fella don't have clue what a dialysis machine looks like, he wouldn't have clue what's going through that Aboriginal's mind... so we need a dialysis patient to work at doing that with 
the staff...partners or the mother to come in and talk about the cultural issues from the dialysis patient perspective. [Man, 50s]

\section{'Stop 'em following us onto the machine'}

Most participants felt concerned about their young people being at risk of CKD. They believed there was an urgent need for prevention programmes to educate young people about their risk factors. Some expressed their desire to be actively involved in this.

\section{'We gotta get em in the schools'}

And that's where the older generation needs to get into the younger ones because they're the next ones, they need to be well educated into what renal failure is all about, because if they don't start at a young age, it's too little too late. [Man, 30s]

They felt education materials they had seen were not relevant to their community, featuring Aboriginal people with a cultural context far removed from theirs. Some wanted to contribute to locally produced educational resources.

I'd like to do a video about my lifestyle, what I done and how I did it, and how I ended up on the dialysis you know. . . sort of not scare 'em, but educate 'em to look after your body, cause your body is very important. [Man, 50s]

\section{'We gotta get em in the schools'}

Participants emphasised the need for health promotion in schools, where their children and grandchildren could be exposed to information about prevention.

\section{'They don't care what they eat'}

It's a good idea going into the schools... when I first got onto the kidney machine, that's one of the first things I thought about. Kids of 20 years old...they got no idea about how much coke and shit that they' re drinkin' how much macdonalds that they're eatin. [Woman, 40s]

\section{DISCUSSION}

Haemodialysis has a devastating impact on rural Aboriginal people, whose lives are disrupted by relocating or travelling long distances to access treatment. ${ }^{12}$ They feel isolated, even within their families, as they struggle to cope with the severe ramifications of life dependent on an acute health system which is culturally alien. Participant stories described individual responses to illness and treatment and problems within the health system; however, all participants identified the family as their motivation for continuing life dependent on HD. These results resonate with other qualitative studies ${ }^{11} 123334$ with family of paramount importance to Aboriginal people, given their relationship obligations originating from traditional kinship structures. ${ }^{35} 36$ The painting of an Aboriginal view of the patient journey was developed by the artist following discussions in the CRG around the analysis. It provides Aboriginal insights into the experience and helps inform improvements to health systems that need to be shaped by family and cultural imperatives.

The study reveals people's shock at late diagnosis and crisis commencement onto HD, depicted in the initial theme. Earlier detection can slow down the progression of CKD. ${ }^{37}$ Despite policy directives aimed at early diagnosis, ${ }^{38}$ this study and similar work finds Aboriginal people still experiencing late diagnosis. ${ }^{12}{ }^{39}$ Discussions with the study's CRG confirmed the need for screening programmes to be provided through primary healthcare settings such as through ACCHS. Increased collaboration between ACCHSs, a trusted healthcare source for many Aboriginal people, ${ }^{35}$ and mainstream health services was seen as key to earlier diagnosis and slowing disease progression.

Lack of predialysis education and understanding of CKD emerged strongly from the data and caused significant distress. These findings are supported by previous studies in remote and metropolitan settings. ${ }^{17}{ }^{40}$ Employing Aboriginal people within renal services to bridge cultural gaps between patients and staff can ameliorate this. An Aboriginal person present during interactions between patients and staff increases cultural safety for Aboriginal patients. ${ }^{35}$ Importantly, the Aboriginal support and advocacy role should occur at diagnosis and at the start of a predialysis pathway. This first theme is cyclically linked to the last where participants expressed a strong desire to educate their children to prevent them following them on their dialysis journey.

Our findings are consistent with studies conducted internationally $^{8}{ }^{9}$ and within Australia ${ }^{15} \quad 17 \quad 41$ where patients reported experiences of disempowerment and dislocation, and a lack of understanding and limited cultural awareness from some service providers and the health system generally. Previous Australian studies confirm the importance of family for Aboriginal people and the negative impact of separation from family on treatment outcomes. $^{12} 41$ Family is the core component of the artwork and also of the study's analysis which highlights the vital role of family in helping people to endure and survive. Health and well-being are inextricably linked to family. ${ }^{42}$ Participants' desire to stay alive for the sake of the family provided motivation to continue treatment and endure the challenging circumstances they faced.

Aboriginal patients often prioritise family commitments over the demands of $\mathrm{HD}^{43}$ as fulfilling family responsibilities is considered to be of greater priority than treatment adherence. This conflict between family and health system obligations raises serious questions about cultural safety when participants must negotiate a health system dominated by non-Aboriginal health professionals who may not understand the importance of family and 'the complexity of the interrelationships 
between Aboriginal people and the places they occupy' (ref. 44, p.19).

Participants' anxiety at the burden of their care on their children illustrates the high levels of morbidity and mortality for Aboriginal renal patients forced to start HD decades earlier than non-Aboriginal people. ${ }^{19} 45$ The despair at the impact of chronic disease on their communities identified in the analysis highlights the early mortality of too many funerals for many Aboriginal people. ${ }^{46}$ Chronic disease resulting in disability and morbidity for people in their $30 \mathrm{~s}$, 40s and 50s requires flexible care models that address the cultural imperatives of Aboriginal patients ${ }^{46} 48$ and their families. This is a worldwide problem recognised by $\mathrm{WHO}^{49}$ and closer to home in New Zealand where a study found that health systems lacked an understanding of the importance of genuine, respectful relationships with patients, citing engagement of whänau (family) as key to service improvement in chronic disease. ${ }^{50}$

Patient-centred care requires healthcare systems to centre on the needs and preferences of patients. ${ }^{51}$ Our study confirms that the relational nature of Aboriginal social structures demands a broader view of patientcentred care, with the focus on family, and confirms that ongoing treatment creates a pressing need for familycentred health services. ${ }^{46}$ This requires culturally competent health systems. Most participants expressed a strong desire for home $\mathrm{HD}$, a cost-effective service model that reduces travel and cross-infection risk when dialysis is removed from hospital settings. ${ }^{52} 53$ This is supported by the artwork where the only 'place' Aboriginal patients want to be is home with family and within the theme of Wish I had one of them nurses to help me at home, with participants reporting inadequate support for home HD staff under existing services. It is arguable that reducing the cost of hospital HD by increasing support for home HD could fund increased home visits and clinical support from renal staff.

Data from our study concur with previous work suggesting that Aboriginal HD patients taking responsibility for their own treatment within their own community have improved their knowledge and understanding of ESKD. There are positive effects from patients feeling secure in their own community and improved health outcomes. ${ }^{17} 54$ A study in remote Australia reported an Aboriginal community controlled renal service as achieving similar health outcomes to non-Aboriginal patients, with improved quality of life. ${ }^{55}$ Aboriginal community control of delivery of HD treatment in a remote location in partnership with good tertiary care can result in health outcomes similar to those of non-Indigenous patients and improve quality of life.

Difficulty in understanding information about their disease and treatment left participants feeling reluctant to engage with clinicians or ask questions. They also felt a lack of cultural safety within renal units, where there was limited understanding of Aboriginal cultural obligations. Aboriginal people in remote Australia and internationally have experienced similar barriers to effective renal care. ${ }^{15}{ }^{17} 56$ Shortfalls in cultural safety limit Aboriginal patients' ability to access information about their disease and treatment. ${ }^{57}$ Participants lacked the confidence to ask questions when they did not understand the information provided. This is further compounded by participant fear resulting from past interactions with health services, when overt racism and discrimination were entrenched within government policies and practice. The 'hands' in the painting signify 'reconciliation' and a closer understanding between Aboriginal patients and their renal clinicians, which the artist envisaged being brought about by this study.

The suggestion that patients themselves deliver cultural awareness to renal staff may improve cultural safety for Aboriginal HD recipients. Staff could learn from Aboriginal patients, thus developing positive reciprocal relationships in their clinical setting. Participants also emphasised education strategies for their children, providing an opportunity for re-empowerment of Aboriginal people disempowered by their ESKD. Involving existing Aboriginal HD patients in this process may be a powerful tool to engage young people, with education and information being delivered by their Elders. ${ }^{46}$ Achieving this would be an important step towards returning self-determination and control to Aboriginal HD patients that reliance on mainstream health services has removed. ${ }^{27}$ The Elders are a preferred source of knowledge about managing chronic disease within Indigenous communities ${ }^{46} 58$

Despite much being published addressing culture and chronic disease, it appears that health services are failing to incorporate these principles into service design and delivery. If renal service provision to Aboriginal people is to improve, the overlapping principles of family-centred care, cultural safety and competence need to be incorporated into policy and practice. This study suggests that Australian health systems have difficulty in understanding how to do this and have not yet succeeded in doing so.

Our study has some limitations. It sought to gain insight into how HD was experienced by Aboriginal people living in rural Australia. The sample was limited to one geographical area; therefore, transferability to other areas is uncertain. The majority of participants were established on HD for longer than 5 years, which may also impact on the generalisability of the findings. This study does not include health economic analysis of potential savings to health services from screening, prevention and increasing home HD services for Aboriginal people; however, this work is clearly needed. This is the first qualitative study to explore the experience and perceptions of rural patients; therefore, it may not concur with findings from metropolitan or remote settings.

\section{CONCLUSION}

The journey for Aboriginal people on HD reinforces the vital role of family as the Aboriginal artist privy to the 
study and its findings depicts in the painting. There is a pressing need for family-centred care services that address current shortfalls in care and acknowledge the importance of family as a treatment modality.

Employing Aboriginal people within renal services to act as conduits between Aboriginal patients and hospital staff can bridge cultural gaps in services. Racism within renal units may be reduced by patients having a higher profile and assisting staff to understand an Aboriginal view.

The late diagnosis of CKD requires an effective screening programme aimed at the prevention and delay of disease progression. Including Aboriginal dialysis recipients in education strategies aimed at informing young people of their risk of CKD could help, with participants suggesting ways to increase the awareness of CKD through their engagement with their own young people.

Acknowledgements The authors sincerely acknowledge the Aboriginal participants in this study for contributing their stories and thank the community reference group members who provided invaluable guidance throughout this study. They also gratefully acknowledge the Bundjalung Nation, on whose lands this research took place.

Contributors EFR designed the study, conducted the interviews, transcribed the interviews, carried out the thematic analysis, drafted the manuscript and met with the Aboriginal community reference group to verify the analysis and gain feedback on the manuscript. LB contributed to the study design, and participated in the thematic analysis and critical review and editing of the first and subsequent manuscript drafts. SW provided intellectual input and critical review, assisted with the thematic analysis and editing of the first and subsequent manuscript drafts and attended meetings with the Aboriginal community reference group to verify the analysis. JS contributed to the study design and ethical approval process, provided a critical review and editing of the first and subsequent drafts and assisted with thematic analysis. AT contributed to the study design, and participated in the thematic analysis and critical review of the first and subsequent manuscript drafts.

Funding EFR was was funded to conduct this study by The Clinical Excellence Commission, lan O'Rourke Scholarship in Patients Safety.

\section{Competing interests None.}

Ethics approval (1) The North Coast Area Health Service (New South Wales) HREC; (2) The University of Sydney HREC; (3) The Aboriginal Health \& Medical Research Council of New South Wales HREC.

Provenance and peer review Not commissioned; externally peer reviewed.

Data sharing statement No additional data are available.

Open Access This is an Open Access article distributed in accordance with the Creative Commons Attribution Non Commercial (CC BY-NC 4.0) license, which permits others to distribute, remix, adapt, build upon this work noncommercially, and license their derivative works on different terms, provided the original work is properly cited and the use is non-commercial. See: http:// creativecommons.org/licenses/by-nc/4.0/

\section{REFERENCES}

1. Australian Institute for Health and Welfare. The health and welfare of Aboriginal and Torres Strait Islander Peoples. Canberra: AIHW, 2008.

2. McDonald SP, Maguire GP, Hoy WE. Renal function and cardiovascular risk markers in a remote Australian Aboriginal community. Nephrol Dial Transplant 2003;18:1555-61.

3. Cass A, Cunningham J, Wang Z, et al. Regional variation in the incidence of end-stage renal disease in Indigenous Australians. Med J Aust 2001;175:24-7.
4. Preston-Thomas A, Cass A, O'Rourke P. Trends in the incidence of treated end-stage kidney disease among Indigenous Australians and access to treatment. Aust N Z J Public Health 2007;31:419-21.

5. Lok P. Stressors, coping mechanisms and quality of life among dialysis patients in Australia. J Adv Nurs 1996;23:873-81.

6. Hagren B, Pettersen I, Severinsson E, et al. Maintenance haemodialysis: patients' experiences of their life situation. J Clin Nurs 2005;14:294-300.

7. Pugsley D, Thomas M. Renal disease in Indigenous populations Nephrology 1998;4:S1-3.

8. Anderson K, Yeates K, Cunningham J, et al. "They really want to go back home, they hate it here": the importance of place in Canadian health professionals' views on the barriers facing Aboriginal patients accessing kidney transplants. Health Place 2009;15:390-3.

9. Kolewaski C. Illness experience and perceived quality of life of Cree from the Mushkegowuk Territory with end-stage kidney disease relocated to an urban centre for hemodiaylsis. [Masters thesis] Schoo of Rehabilitation Therapy. Kingston: Queens University, 2007.

10. Preston-Thomas A, Cass A, O'Rourke P. Kidney disease in Aboriginal and Torres Strait Islander people. Aboriginal Islander Health Worker J 2007;31:3-5.

11. Burnette L, Kickett M. Dislocation and dialysis in Aboriginal patients with renal failure. Aboriginal and Islander Health Worker $J$ 2009;33:10-13

12. Anderson K, Cunningham J, Devitt D, et al. "Looking back to my family": Indigenous Australian patients' experience of hemodialysis. BMC Nephrol 2012;13:114.

13. Australian \& New Zealand Dialysis \& Transplant Registry. ANZDATA Registry Report. 33rd edn. Adelaide: ANZDATA, 2010.

14. Morehouse RE, Colvin E, Maykut P. Nephrology nurse-patient relationships in the outpatient dialysis setting. Nephrol Nurs $J$ 2001;28:295-300.

15. Burnette L, Kickett M. 'You are just a puppet': Australian Aboriginal people's experience of disempowerment when undergoing treatment for end-stage renal disease. Renal Soc Australas J 2009;5:113-18.

16. Devitt J, McMasters A. Living on medicine: a cultural study of end-stage renal disease among Aboriginal people. Alice Springs: IAD Press, 1998.

17. Preece C. Developing a model of care to improve the health and well-being for Indigenous people receiving renal dialysis treatment. [Masters thesis]. Queensland University of Technology, 2010.

18. Australian Bureau of Statistics. The Health and Welfare of Australia's Aboriginal and Torres Strait Islander Peoples. Canberra: Australian Bureau of Statistics, 2008.

19. Australian Institute of Health and Welfare. The health and welfare of Australia's Aboriginal and Torres Strait Islander people: an overview 2011. Canberra: AlHW, 2011.

20. Wilson S. What is an Indigenist research paradigm? Can J Native Educ 2007;30:193.

21. Martin KL. Please knock before you enter: Aboriginal regulation of outsiders and the implications for researchers. Teneriffe: Post Pressed, 2008.

22. D'Alonzo KT. Getting started in CBPR: lessons in building community partnerships for new researchers. Nurs Inq 2010;17:282-8.

23. Atkinson J. Privileging Indigenous research methodologies. Indigenous Voices Conference. Cairns, 2001.

24. Rigney L-I. Internationalization of an Indigenous anticolonial cultural critique of research methodologies: a guide to Indigenist research methodology and its principles. J Native Am Stud 1999;14:109-21.

25. Weber-Pillwax $\mathrm{C}$. What is Indigenous research? Canadian J Native Educ 2001;25:166-74.

26. Wilson S. Research as ceremony: Indigenous research methods. 1st ed. Winnipeg: Fernwood Publishing, 2008.

27. Rix EF, Barclay L, Wilson S. Can a white nurse get it? 'Reflexive practice' and the non-Indigenous clinician/researcher working with Aboriginal people. Rural Remote Health 2014;4:2679. (on-line)

28. Richards L, Morse JM. Read me first for a user's quide to qualitative methods. 3rd edn. Thousand Oaks: Sage Publications, 2013.

29. Bessarab D, Ng'andu B. Yarning about yarning as a legitimate method in Indigenous research. Int $J$ Crit Indigenous Stud 2010;3:37-50

30. Kovach M. Conversational method in Indigenous research. First Peoples Child Fam Rev 2010;5:40-8.

31. Strauss AL. Qualitative analysis for social scientists. New York: Cambridge University Press, 1987.

32. Lawrence M, Dodd Z, Mohor S, et al. Improving the patient journey: achieving positive outcomes for remote Aboriginal cardiac patients. Darwin: Cooperative Research Centre for Aboriginal Health, 2009.

33. Bennett E, Manderson L, Kelly B. et al. Cultural factors in dialysis and renal transplantation among Aborigines and Torres Strait 
Islanders in North Queensland. Aust J Public Health 1995;19:610-15.

34. Rivalland P. It's more than machines and medicine: they should understand there's a Yanangu way. Darwin: Western Desert Nganampa Walytja Palyantjaku Tjutaku Aboriginal Corporation \& CRCAH, 2006.

35. Taylor K, Guerin P. Health care and Indigenous Australians: cultural safety in practice. 1st edn. South Yarra: Palgrave Macmillan, 2010.

36. Bourke E. The first Australians: kinship, family and identity. Fam Matters 1993;35:4-6.

37. Hoy WE, Wang Z, Baker PRA, et al. Reduction in natural death and renal failure from a systematic screening and treatment program in an Australian Aboriginal community. Kidney Int 2003;63(S83): S66-73.

38. New South Wales Health. Kidney health check: promoting the early detection \& management of chronic kidney disease. Sydney: Department of Health, NSW, 2010.

39. Hoy WE, Davey RL, Sharma S, et al. Chronic disease profiles in remote Aboriginal settings and implications for health services planning. Aust N Z J Public Health 2010;34:11-18.

40. Cass A, Lowell A, Christie M, et al. Sharing the true stories: improving communication between Aboriginal patients and healthcare workers. Med J Australia 2002;176:466-70.

41. Devitt J, McMasters A. “They don't last long”: Aboriginal patient experience of end-stage renal disease. Nephrology 1998;4:S111-17.

42. National Aboriginal Health Strategy Working Party. National Aboriginal health strategy. Canberra: NAHSWP, 1989.

43. Rix EF, Barclay L, Wilson S, et al. Service providers' perspectives, attitudes and beliefs on health services delivery for Aboriginal people receiving haemodialysis in rural Australia: a qualitative study. BMJ Open 2013;3e003581.

44. Fredericks $B$. What health services within rural communities tell us about Aboriginal people and Aboriginal health. Rural Soc 2010;20:10-20.

45. Stumpers S, Thompson N. Review of kidney disease and urologic disorders among Indigenous people. MountLawley: Edith Cowan University, 2013.
46. Aspin C, Brown N, Jowsey $\mathrm{T}$, et al. Strategic approaches to enhanced health service delivery for Aboriginal and Torres Strait Islander people with chronic illness: a qualitative study. BMC Health Serv Res 2012;12:143.

47. Australian Indigenous Health InfoNet. The context of Indigenous health. Perth, 2012. http://www.healthinfonet.ecu.edu.au (accessed 2013).

48. Durey A, Wynaden D, Thompson SC, et al. Owning solutions: a collaborative model to improve quality in hospital care for Aboriginal Australians. Nurs Inq 2012;19:144-52.

49. World Health Organization. Innovative care for chronic conditions: building blocks for action, global report. Geneva: World Health Organization, 2002.

50. Kidd J, Gibbons V, Kara E, et al. A whänau ora journey of Maori men with chronic illness: a Te Korowai analysis. AlterNative 2013;9:125-41.

51. Harkness J. Patient involvement: a vital principle for patient-centred care. World Hosp Health Serv 2005;41:12-16.

52. North Coast Area Health Service. Supporting home-based dialysis implementation plan 2009-2014. Lismore: North Coast Area Health Service, 2009

53. Department of Health Western Australia. Framework to improve home dialysis therapy in Western Australia. Perth: Department of Health WA, 2011.

54. Villarba A, Warr K. Home haemodialysis in remote Australia. Nephrology 2004;9:S134-7.

55. Marley JV, Dent HK, Wearne M, et al. Haemodialysis outcomes of Aboriginal and Torres Strait Islander patients of remote Kimberley region origin. Med J Aust 2010;193:516-20.

56. Salvalaggio G, Kelly L, Minore B. Perspectives on health: experiences of First Nations dialysis patients relocated from remote communitities. Can J Rural Med 2003;8:19-24.

57. Westwood B, Westwood G. Aboriginal cultural awareness training: policy v. accountability-failure in reality. Aust Health Rev 2010;34:423-9.

58. Sanderson PR, Little M, Vasquez M, et al. A perspective on diabetes from Indigenous views. Fourth World J 2012;11:57-78. 